\title{
Addressing energy system modelling challenges: The contribution of the Open Energy Modelling Framework (oemof)
}

\author{
Simon Hilpert ${ }^{1^{*}}$, Stephan Günther ${ }^{1 \bullet}$, Cord Kaldemeyer ${ }^{2 \bullet}$, Uwe Krien ${ }^{3 \bullet}$, Guido Pleßmann ${ }^{3 \bullet}$, Frauke \\ Wiese $^{4 \odot}$, Clemens Wingenbach ${ }^{1 \odot}$ \\ 1 Department of Energy and Environmental Management, Europa-Universität Flensburg, Flensburg, \\ Germany \\ 2 Department of Energy and Biotechnology, University of Applied Sciences Flensburg, Flensburg, Germany \\ 3 Reiner Lemoine Institut gGmbH, Berlin, Germany \\ 4 Department of Management Engineering, Technical University of Denmark, Lyngby, Denmark \\ * Corresponding author: \\ E-mail: simon.hilpert@uni-flensburg.de (SH) \\ PThese authors contributed equally to this work.
}

\section{Abstract}

The process of modelling energy systems is accompanied by challenges inherently connected with mathematical modelling. However, due to modern realities in the 21st century, existing challenges are gaining in magnitude and are supplemented with new ones. Modellers are confronted with a rising complexity of energy systems and high uncertainties on different levels. In addition, interdisciplinary modelling is necessary for getting insight in mechanisms of an integrated world. At the same time models need to meet scientific standards as public acceptance becomes increasingly important. In this intricate environment model application as well as result communication and interpretation is also getting more difficult.

In this paper we present the open energy modelling framework (oemof) as a novel approach for energy system modelling and derive its contribution to existing challenges. Therefore, based on literature review, we outline challenges for energy system modelling as well as existing and emerging approaches. Based on a description of the philosophy and elementary structural elements of oemof, a qualitative analysis of the framework with regard to the challenges is undertaken. Inherent features of oemof such as the open source, open data, non-proprietary and collaborative modelling approach are preconditions to meet modern realities of energy modelling. Additionally, a generic basis with an object-oriented implementation allows to tackle challenges related to complexity of highly integrated future energy systems and sets the foundation to address uncertainty in the future. Experiences from the collaborative modelling approach can enrich interdisciplinary modelling activities.

Our analysis concludes that there are remaining challenges that can neither be tackled by a model nor a modelling framework. Among these are problems connected to result communication and interpretation. 


\section{Introduction}

Modelling of energy systems has a long tradition since linear programming was first used for capacity expansion planning of generators in regulated markets in the 1950s [1]. After the oil crisis in 1970s, due to environmental concerns, the focus moved from capacity planning towards sustainable energy supply [2]. In recent years, global warming concerns have stipulated an energy system transformation process in many countries. This process has led to an ongoing shift from mainly large scale, centralized and dispatchable generators to smaller and more distributed plants with mainly intermittent supply characteristics. As a result, energy systems face an increasing demand for flexibility and stronger cross-sectoral integration between the energy sectors electricity, heat and transport [3]. Besides this, modern realities are characterised by fast changing environments and various events with disruptive character. Examples are the nuclear phase-out in Germany, the liberalization of markets, an increasing importance of public acceptance and fast developing, vastly expanding information technology. Such conditions with implications for the overall economy require an evolution of models to give guidance in a diverse set of questions. Amongst others, this includes grid control and planning, dispatch and unit commitment, expansion planning, energy market design and environmental analysis of highly integrated energy systems.

Like other research disciplines that apply mathematical models, energy system modelling faces challenges that are associated with deriving findings from a mathematical representation of the real world. Additionally, energy systems research has to deal with domain-specific challenges that arise from or aggravate with modern realities [3]. The demand for a cross-sectoral and more integrated analysis of energy systems increases complexity in energy system modelling. For example, models need to cover a high temporal and spatial resolution of distributed energy systems with renewable energies while simultaneously looking at long time horizons and large geographical areas [3]. Different types of uncertainty may also affect results obtained from energy system models [4-6]. Furthermore, energy is a driver of economic growth [7] and interacts with essential goods like water and food [8]. Consequently, energy research is closely linked to other research disciplines. In the light of resource scarcity and environmental concerns, interdisciplinary research consequently becomes increasingly important [9]. At the same time, there exists a serious social responsibility for modellers as model results are widely used to support policy decisions [10]. Therefore, adhering to scientific standards in energy system modelling is an important matter for model development and application. As a consequence, the issue of transparency is a recurring point in literature [11-13] and emerging initiatives in the energy modelling community (e.g. the open energy modelling initiative [14]) advocate scientific principles in energy systems research. Linked to the policy relevance of model based research, the modeller decision-maker interface is another challenge $[10,15,16]$. Several approaches for handling some of these challenge exist. Those range from addressing uncertainty [5], integrated modelling [17], model-linking [18-20] to transparent modelling [11,21].

With the development of the Open Energy Modelling Framework (oemof) we go one step further. This framework provides a generic core structure that facilitates the development towards a wide-ranging energy system modelling suite. It follows a strict non-proprietary software and open source philosophy and has been developed collaboratively. The objective of this paper is twofold: (1) we present oemof as a novel approach of collaboratively modelling energy systems, and (2) analyse how and to what extend oemof contributes to address current energy system modelling challenges.

Based on a literature review we delineate a classification of current challenges in energy system modelling. Subsequently, we describe the philosophy, concept and the implementation of the newly developed framework. To illustrate its scope, we then describe the process of building an application and present existing application examples. Based on these two sections, the contribution of oemof to address current energy system modelling challenges is assessed in the form of a qualitative analysis. The remaining challenges and associated problems in the energy modelling field will be discussed ahead of drawing final conclusions. 


\section{Challenges in energy system modelling}

It has already been mentioned by other authors that the field of energy system modelling and its models may seem opaque to outsiders $[22,23]$. One reason for this may be the broad definition of the term energy system model. Depending on the research question, energy system models may range from detailed, highly technical models of small sub-systems to large pure economic models covering whole economies. Typical criteria for categorizing models are top-down (macro-economic relationship of components) vs. bottom-up approaches (technology specific), simulation vs. optimization of the system being studied and partial equilibrium (e.g. considering only the power sector) vs. equilibrium models (considering the whole economy) [24]. For a comprehensive description of the model landscape as well as of model topologies we refer to existing reviews $[3,23,25,26]$. We will restrict our analysis to the general challenges in the field of energy system modelling. These challenges relate to steps in the modelling process as described by [6], ranging from the development of a mental model of an energy system to the application of the model including the communication of results.

Coming up with a classification scheme for energy modelling challenges can be compared to proposing a scheme for energy model classification with respect to the generality of the categories. In the case of energy system models, various options of classifying models exist, though there are 'few models - if any - that fit into one distinct category' $[27$, p.7]. This is similarly true for categorization of energy system modelling challenges. For our analysis we propose the five major challenge categories complexity, uncertainty, interdisciplinary modelling, scientific standards, and model utilization, which are characterized by different relevant aspects and shown in Table 1. Generally, the relevance of a challenge for specific models may vary as it is determined by the focus of the underlying research question. A detailed description of the challenges will be given in the following sections.

Table 1. Challenges of energy system modelling.

\begin{tabular}{lll}
\hline Challenge & Aspects & Literature \\
\hline Complexity & sector coupling, temporal or regional resolution, input data, & {$[3,24,26]$} \\
& result processing & \\
Uncertainty & epistemic, aleatory, linguistic, decision, planning & {$[5,6,28]$} \\
Interdisciplinary Modelling & inclusion of human dimension, energy-water-food nexus & {$[9,12,29]$} \\
Scientific Standards & $\begin{array}{l}\text { transparency, repeatability, reproducibility, scrutiny, scien- } \\
\text { Model Utilization }\end{array}$ & {$[13,16,30-32]$} \\
& tific progress & \\
\hline
\end{tabular}

\section{Complexity}

As mentioned above, the main driver for a rising complexity is the transformation of energy systems in combination with the liberalization of markets as described in the introduction. Diversification, distributed production and stronger integration of energy sectors with versatile interdependencies is a growing challenge for the energy modelling community.

Considering the power-heat-transport nexus, integrated models play a decisive role today in providing insight on different flexibility options [35], using excess electricity in an economic way [36] and for meeting climate targets [37]. While a high spatial and temporal resolution is required to consider varying weather influence and cover different flexibility options, spatial and temporal coverage is also necessary for long-term development of an increasingly interconnected power system. For instance, Després et al. [24] conclude that long-term energy models would benefit from an improved representation of variable renewable energies in the power sector. The growing requirement of flexibility in particular on the demand side (e.g. storages or 
demand side management) additionally increases modelling complexity in systems with high penetration of renewable energies.

Although computing resources have been improved significantly in recent years, decisions between model complexity and runtime need to be taken with regard to optimization algorithms. Attempts in tackling complexity have been made by applying models in a consecutive or interactive manner. For instance, Deane et al. $[18,19]$ soft-link an energy system model with a dedicated power system model. Similarly, Trepper et al. [20] present an integrated approach to assess potential benefits of market splitting in Germany by connecting a European dispatch model to a detailed unit commitment scheduling model. With the liberalization of markets, heterogeneous participants with different objectives and new business-cases are difficult to model with classical optimization models that traditionally have been applied in oligopolistic markets. Here, agent-based models have been proposed as a useful tool to test market design [38]. In general, agent-based modelling is applicable to complex systems across different domains and disciplines [39]. With the objective to represent and cover market behaviour, agent-based models like EMACS (Electricity Market Complex Adaptive System) [40] are applied to electricity markets. In this context, such models can for example be applied to assess cross-border effects of $\mathrm{CO}_{2}$-policies [41] or the complex interactions of the huge variety of actors caused by policy measures to integrate renewable energies into the market [42]. Although agent-based models can be applied as a classical economic approach capturing the complexity of market actor interactions, it is increasingly utilized to also capture the human dimension which is referred to in the context of interdisciplinary modelling (see section Interdisciplinary modelling).

The increasing complexity of models is accompanied by a rising amount and complexity of input and result data. Data are crucial because absence of necessary data may hamper the development of new modelling techniques, as Krysiak and Weigt [43] argue in the case of demand side management modelling. Keirstead et al. [26] state that data availability is one challenge for (urban) energy system modelling. Acquiring or generating input data is not a trivial task as it requires versatile software skills (e.g. GIS, databases, reverse engineering) and may be linked to other sophisticated research areas (e.g. meteorology in the case of power production from wind turbines). Therefore, data processing to generate model input data can be one of the most time consuming tasks in the whole modelling process.

Regarding the output, models usually produce large amounts of data that have to be analysed. Therefore, result processing itself may be difficult and time-consuming. This affects for example the visualization of multi-dimensional data (temporal, regional, unit-wise) in an appropriate way. The complexity challenge is linked to the challenges of model utilization. There exists a trade-off between modelling complex interactions with the required level of detail and keeping the model clear and comprehensible.

\section{Uncertainty}

Uncertainty has been identified as a challenge for energy system modelling decades ago [44]. Craig et al. [4] state that uncertainities in long-range energy forecasts are systematically underestimated. Uncertainty in terms of energy system modelling can be classified into a number of types. Generally, literature has different scopes, approaches, and scientific backgrounds to classify uncertainty which results in different classification schemes $[3,5,6]$. Mirakyan and Guio miss a 'common agreement on typology of uncertainty' [6]. They propose a new framework that has a broader scope and a more detailed classification compared to uncertainties described by Pfenninger et al. [3] and Hunter et al. [5]. This framework for categorization of uncertainty incorporates energy system modelling, decision making and subsequent planning processes: (1) linguistic uncertainty, (2) knowledge or epistemic uncertainty, (3) variability or aleatory uncertainty, (4) decision uncertainty, (5) planning procedural uncertainty and (6) level of uncertainty.

Even though not very often discussed in the context of energy modelling, linguistic uncertainty (1) affects energy system planning and decision making based on model results. Linguistic uncertainty arises from natural language being vague, ambiguous, and because meaning of words may change over time [45]. An illustrative example is the ambiguous usage of the term model. 
Knowledge or epistemic uncertainty (2) covers various aspects of uncertainty related to context or framing, data, structure of a model, technical and accumulated uncertainty that includes all other. Various examples for this type of uncertainty exist in literature as this category covers a wide range. Assumed learning rates and consequently future costs, (e.g. for renewable energy technologies) are decisive parameter for energy system models [46] as those often aim for minimal total system costs. If not carefully chosen, biased results may lead to incorrect policy recommendations if they do not reflect the sensitivity of this assumption [47]. Methodology and key pitfalls of assessing future costs of energy technologies based on learning rates is an important topic among the research community [48-50] that illustrates the importance of dealing with uncertainty related to input data.

Uncertainty arising from structure of a model is the second major subcategory and lies in the nature of models. Due to the complexity of the real world, a model is always a simplified representation of real systems. Linearised description of energy systems is one prominent example of necessary simplification applied in models that may have strong impact on results [51]. Structural uncertainty has special importance for long-term planning models as they may cannot be fully validated [52]. Although tackling structural uncertainty is tricky, one attempt is made by DeCarolis et al. [53], who explore the near-optimal decision space with the technique modelling to generate alternatives (MGA) [28].

Variability or aleatory uncertainty (3) refers to 'inherent variability manifested in natural and human systems' [6]. It can also be referred to as random or stochastic. Variability can be addressed with established mathematical methodologies. For example, the open source model TEMOA applies stochastic programming [5] to deal with variability uncertainty. For deterministic models other options are scenario and sensitivity analysis or Monte Carlo simulations.

Decision uncertainty (4) stems from decision makers with a different understanding and judgement of objectives and appropriate solutions and strategies [6]. For example risk perception or the way of representing model results to decision makers may affect their decision [45]. Availability of resources in terms of information and time to process it affects decision making as well [6]. According to Wardekker et al. [54], uncertainty perception varies depending on how information is provided. This relates Planning procedural uncertainty to the aforementioned decision uncertainty.

Additionally to the presented types of uncertainty, the level of uncertainty (6) has to be considered [6]. It describes the environment in which a decision is made. Four levels for distinction are proposed: deterministic, risk laden, uncertain and ignorant environments [6].

\section{Interdisciplinary modelling}

The development of energy system models is typically undertaken from an engineering or economic perspective. Though, Jefferson [55] argues that emphasizing on equations and economic theories is hindering to focus on complicated factors and their future implications. Furthermore, Wiese [12] states that twenty-first century challenges need to include other perspectives than least-cost optimization. As stated above, differences are inevitable between ideal results of optimization models with one single rational decision maker and real world developments with a multitude of heterogeneous actors [56]. In addition to an increased complexity, this is also a challenge from an interdisciplinary view because modellers need to integrate perspectives that are not captured by standard economic or engineering approaches. However, if energy research is not undertaken in an interdiciplinary way, researchers 'are not likely to grasp the problems, and thus the solutions to this challenging (energy) research space' [9, p.247].

Social and behavioural factors are import to assess the adoption of renewable technologies $[57,58]$ or the representation of consumer's real behaviour in classical energy models [59]. For example, social acceptance has a relevant impact on grid and wind power expansion [60,61]. Thus, attempts exist to capture the human dimension in energy system modelling by applying social science methods. But considering the strong interconnectedness of energy systems and society, social sciences are rather under-represented in contemporary energy research [62]. 
Another requirement in interdisciplinary modelling results from the strong interdependencies between the energy, water and food sector. Granit et al. [29] argue that increased understanding of the water-energy-food nexus is necessary to achieve sustainable development goals. They present first attempts for integrated tools and state that further cooperation between the modelling disciplines is required.

To comprehend the dimension of challenges in interdisciplinary energy modelling, one has to consider that finding a coherent terminology and taxonomy within one field is already complex. This is referred to as linguistic uncertainty in the section Uncertainty. Between different disciplines, a lack of understanding due to different terms impedes a common understanding of energy systems.

\section{Scientific standards}

Complying with scientific standards includes transparency, repeatability, reproducibility and scrutiny. These principles ensure that science moves forward and can perform course corrections through independent verifications [63]. Beyond that, these are also fundamental for the societal process, which depends on return of knowledge that has been publicly funded. Repeatability or the sometimes used equivalent term replicability describes the ability to repeat an experiment and come to the same results. In contrast, reproducibility means that results can be repeated by a different researcher in a different computer environment [64]. Although definitions exists, these two terms are not always utilized with this clear distinction in literature.

Transparency of methods, code and data lays the foundation for the other three principles, as it is a precondition for building up on existing scientific work. However, Ince et al. [32] state that for computational science transparency at all stages constitutes a basic condition for reproducibility. Even if this is fulfilled, reproducibility remains a challenging task due to hardware, software and natural language uncertainty. The aspect of constantly changing model versions in energy system models and the lack of precisely describing these when presenting results adds another dimension to the challenge of reproducibility [22]. As Pfenninger et al. [65] argue, full - meaning effective - transparency of energy system models is still hampered by different barriers. Specifically, the lack of open licenses on the original sources of data is an obstacle for making model data publicly available. Moreover, a sparse or lacking documentation of data makes it inconvenient for others to use these data.

To facilitate repeatable analysis, DeCarolis et al. [13] recommend five steps of best practices in energy economic optimization model development. These steps, we argue, can and should be extended to every energy system model:

(1) Make source code publicly accessible, (2) Make model data publicly accessible, (3) Make transparency a design goal, (4) Develop test systems for verification exercises, (5) Work towards interoperability among models. In fact, with today's information technology it has never been easier to comply with these recommendations. And indeed, source code of different models has been made publicly accessible in recent years (Balmorel [21], OSeMOSYS [11], TEMOA [5], calliope [66], PyPSA [67]). On the website of the open energy modelling initiative, up to now 25 open energy models are registered [14]. Contrary to increasing model transparency, publishing solely aggregated results of energy system models is still a common procedure. For instance, a list of models used in the UK shows that input data and code of the majority of models are not open [23]. As almost any result can be generated by modifying decisive input data, variables or code, the common practice makes repeatable results impossible. Attempts exist to overcome these problems. Regarding data, the Dataverse project is one example of technical support in linking associated data with the published article [68].

While point three on the list (transparency as a design principle) has already been discussed above as the foundation, the fourth point (verification exercises) refers to scrutiny. The importance of scrutiny for energy system modelling is discussed in the following in a technical sense but also on the societal level. Point five rather relates to applicability and re-usability which is discussed related to model utilization.

On the technical level, scrutiny refers to identifying inconsistencies or faults (so called bugs). Every computer model is prone to bugs, whereas the probability of theses errors increases along with the complexity and size of the model. Detecting bugs is particularly vital in energy system modelling, as small errors may have great impact on the results. Johnson [69] highlights that peer-reviewed open source software has significant 
advantages related to bug findings. Besides this, Ndenga et al. [70] point out that the size of a community, i.e. users and developers, is one metric for bug reports.

On a societal level, scrutiny refers to the detection of bias in model code and data. The possibility to scrutinize model results is essential for credibility [16] and the development of public trust in the modelling results, particularly as participation in the design of energy pathways becomes increasingly important [31]. Being widely utilized for policy advice, the trade-off between being policy-relevant without being policyprescriptive is of vital importance for model-based research [30]. Though, Mai et al. [16, p.9] conclude that, accidentally or purposefully, all models incorporate bias. Going one step further, Biewald et al. [71] argue that value-laden and ethical issues cannot and should not be avoided in model-based studies, but assumptions based on ethical opinions should be communicated transparently which can increase policy relevance of these studies. Similarly Edenhofer and Kowarsch [72] state that value-neutral scientific recommendations for public policy means are not possible. As model based research has to deal with normative-ethical aspects, they suggests a new culture in academia that defines the role of modellers as cartographers of solution spaces. Detecting value-laden assumptions is even more difficult than detecting bugs, as software tests fail at this. Hence, again transparency of source code and data is pivotal for energy model usage in policy advice and essential for complying with quality standards [15].

Although all discussed points also refer to all computational heavy sciences, Pfenninger et al. [65] argue, that energy policy research is lacking behind other fields in terms of complying with scientific standards.

\section{Model utilization}

The issue of model utilization is linked to growing model complexity. In the modelling process, three main groups of persons are involved: (1) developers (2) users and (3) decision makers. It is noteworthy that in some cases these groups may not be completely distinct, as developers and users might be identical. In terms of model utilization we identify two main aspects. Firstly, the challenge of usability that is associated with the model user - decision maker interface. Secondly, the challenge of applicability that can be understood as a problem of 'ease of use' at the developer-user or 'ease of adaptation' at the developer-developer interface.

As models only produce useful information if the recipients understand the causal relations, there remains a trade-off between the level of complexity and the general usability. Bale argues that '[m]odellers need to engage with their beneficiaries from the outset so that models are properly scoped and fit for purpose.' [34, p.157]. Most notably this is important as models are made for obtaining insight not for generating numbers [73].

The challenge of finding a common language between developers, users and recipients of their results exists almost as long as the models themselves. In 1976, the Energy Modelling Forum was formed to 'foster better communication between the builders and users of energy models in energy planning and policy making' [33, p. 449]. Energy research is generally application-oriented but stands out among other policy fields with externalities. Due to its vertical and horizontal complexity, entailed costs and strong path dependency, energy models are indispensable for policy support [74]. However, the decision maker's idea of useful information may significantly disagree with those of the users' point of view [16, p.9]. This is a crucial point, as '[a] model is not fit for purpose if it is developed without sufficient critique of the motives for producing the model.' [34, p.155]. Therefore, the communication of results is a crucial aspect of the modelling process. In particular, valuable information may not only be lost at the user-decision maker interface. To tackle this problem in operations research, the concept of model assessors, analysing and evaluating models for decision makers has come up long time ago [75]. Additionally, Strachan et al. [10] propose further improvements like platform-based expert user groups for coordination and interdisciplinary external stakeholder review for energy system models.

Between developers and users, an easier and better understanding of model mechanisms than at the developer-decision maker interface could be assumed. Unfortunately this seems not always to be the case. One example for differences in understanding models and results is the discussion about results from the NEMS model (see [76] and [77] for details). The usefulness of a model rises if it can be applied to a diverse set of problems and by different researchers. Ideally, the expense of a developer for building up on an 
existing model should be lower than the expense for building a new one. In the context of energy system modelling it has been argued that '[s]ociety as a whole saves time and money if researchers avoid unnecessary duplication' [65, p.212]. Considering the rising amount of open energy models for similar purposes [14], it yet seems that developers tend to rather develop a new model instead of using existing ones. A reason for this may be the rising complexity and different software skills required to adapt models. Consequently, being open does not seem to be sufficient in terms of usability, even if a deep modelling understanding exists. The problem of applicability is also connected to scientific standards as it is vital for the repeatability and more importantly to the reproducibility of results.

\section{The framework concept}

\section{Philosophy and delimitation}

The framework was conceived as a community project to take advantage of similar modelling activities. Due to the different research backgrounds of the collaborators, the framework was not designed for the scope of one particular application. Instead, the idea was to create a framework that can be used to build a variety of energy system models by simplifying recurring processes in the field of energy system modelling. Thus, users still need to have a general understanding of the problem and its associated model. Hence, oemof's target group are energy system model developers.

Existing open source frameworks like calliope presented by Pfenninger et al. [66] and the toolbox OseMOSYS presented by Howells et al. [11], are designed to build specific models of one model family or type by the use of predefined sets of equations (e.g. bottom up linear optimization based models). The URBS model generator written in GAMS is a similar example [36]. Our work tries to encompass these valuable approaches while going one step beyond to facilitate the modelling of complex energy systems. It provides a rich set of tools that can be understood as encapsulated sub-frameworks allowing one to model today's and tomorrow's energy systems. This includes optimization libraries as well as tools to simulate feed-in from renewable energy sources or local heat demand for a specific region. Furthermore, the framework needs to be embedded in a surrounding infrastructure for pre- and post-processing of data to support complete workflows. This requires well defined interfaces between existing tools and a common foundation. In the case of oemof, the fact that its developers come from different modelling backgrounds and have differing objectives resulted in a generic foundation for the framework.

Therefore, oemof is neither focused on a specific analytic or mathematical approach nor restricted to a certain spatial or temporal resolution. Moreover, the description of the energy system is separated from the actual calculations done on the system (e.g. linear optimization) because this mathematical approach is just one way of simulating the system. Essentially, energy systems ranging from distributed or urban ones to energy systems on a national scale may be modelled, making the framework a multi-purpose modelling environment.

\section{Community}

Oemof was created as a community project and is still being developed as one. Working groups from different institutions aimed to develop a modelling environment that satisfies their different scientific scopes. In order to consolidate their internal models into a common one that is used jointly by the different working groups, development and communication processes have to be established to facilitate collaboration. These processes will in turn enable a seamless integration of new community members into the development process, thus helping to expand the community. Furthermore, the oemof community tries to get users, who are not developers, involved as early as possible.

To satisfy the requirements of the different groups and projects, the framework has to be flexible and adaptable. Furthermore, the produced code has to be well documented in order to be accessible and easily 
modifiable for different contributors of various institutions. To enable the communication between all developers and users, a collaborative platform is used that is still under active development.

\section{Concept}

The main feature of the framework is that of separating the issue of describing an energy system's topology from calculating the information about the system one is interested in. To achieve this, we developed a generic concept which constitutes the foundation of all oemof libraries. In this generic concept an energy system is represented as a network consisting of nodes which are connected via flows. Nodes are subdivided into buses and components. When representing an energy system, we impose the additional constraint, that buses are solely connected to components and vice versa. Components are meant to represent actual producers and consumers of the energy system, while buses are meant to represent how these components are tied together. Flows are used to represent the inputs and outputs of a component. An energy system that is represented in such a way can be approached mathematically using concepts from graph theory by looking at it as a bipartite graph, where nodes are partitioned into buses and components while flows act as the directed edges of the graph. The framework provides basic components which can be used directly while also facilitating the development of more specific components built upon the basic ones. A detailed description of the core concept with its theoretical foundation has been published by Wingenbach et al. [78]. An example of how to describe an arbitrary energy system using this network structure is shown schematically in Fig 1.

Energy System

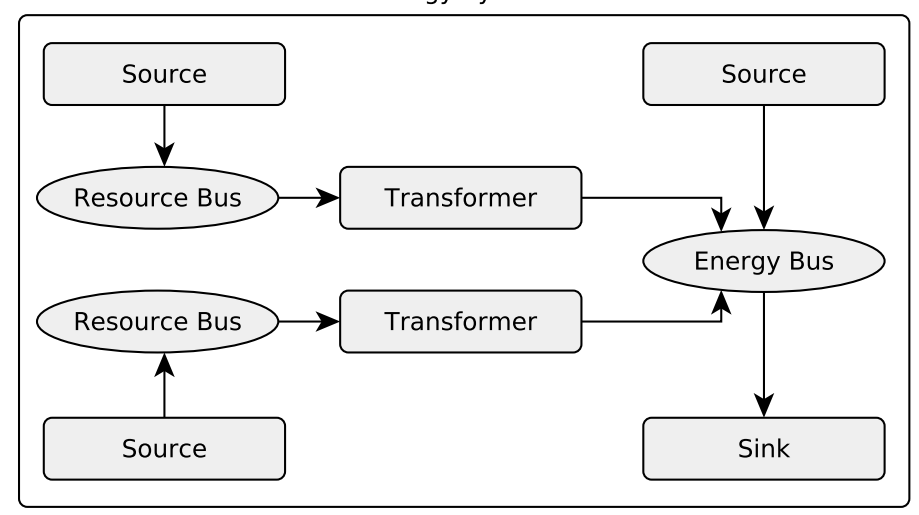

Fig 1. Schematic illustration of an energy system represented as an oemof network.

Based on the flows present on each component, they can be divided into three main subtypes representing different physical objects:

(1) Transformers have inflows and outflows. For example a gas turbine consumes gas from a gas bus and feeds electrical energy into an electricity bus. The relation between inflow and outflow can be specified in the form of parameters, for example by specifying the transfer function or an efficiency factor. In the case of a gas turbine, the efficiency factor would be the simplest way of relating the resource consumption to the provided energy.

(2) Sinks only have inflows but no outflows. Sinks can represent consumers of which households would be an example.

(3) Sources have outflows but no inflows. For example, wind energy or photovoltaic plants can be modelled as sources. 
A similar, purely mathematical formulation of multi-commodity network flow models for dynamic energy management has been illustrated in 2012 by Zeng and Manfren [79]. Furthermore, related structures of energy systems can also be found in different energy models [11,80,81]. These publications demonstrate that using a graph is an intuitive way of representing an energy system. Being an openly available, uniform, sector-independent framework that provides a consistent object-oriented implementation of the generic network structure makes oemof a valuable contribution to the energy modelling and especially the energy framework family.

\section{Implementation}

The framework and its underlying concept is implemented using an object-oriented approach in the high-level programming language Python. It consists of different libraries that can be grouped according to their mutual compatibility, resulting in the layer structure shown in Fig 2.

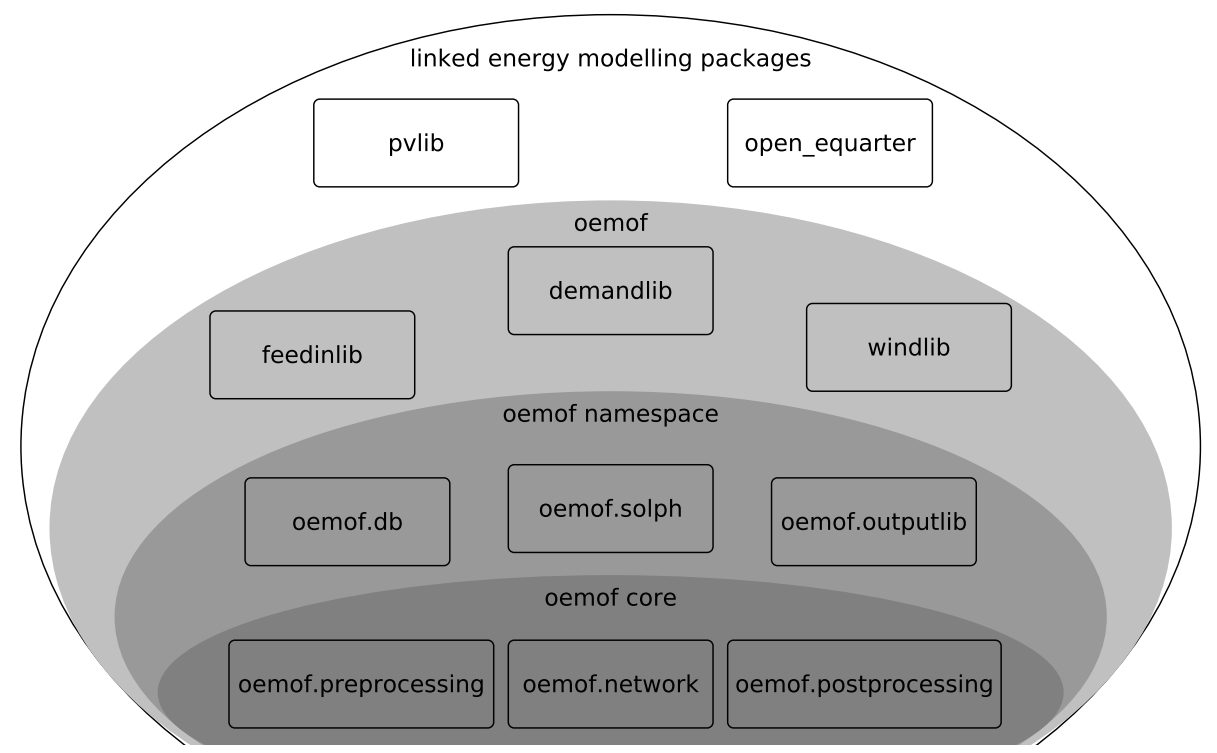

Fig 2. Libraries located on different oemof layers.

Four main layers can be used to categorize the libraries:

(1) At the core layer the generic graph structure is implemented. At this layer the basic application programming interface (API) is defined. Additionally, the description of an energy system as well as the format of input and output data for core-objects is defined.

(2) The namespace layer contains associated libraries that are based on the core APIs and inherit from core-objects. These could be libraries for cost or power-flow optimization or other purposes.

(3) The so-called oemof layer contains libraries associated with oemof which can be used independently but also provide means to integrate with oemof, in case one want use both.

(4) Finally, the outermost linked packages layer includes open source projects known to be used by or to use libraries from the layers below. These open source projects complete the toolbox for energy modelling. With this layer we take advantage of synergies with energy related open source projects that link to or are linked to the framework. 
The network concept has been implemented at the core layer in form of a class hierarchy which is sketched in Fig 3. The root elements of this class hierarchy are Node, Flow and EnergySystem. Node is the abstract base class for Bus and Component, which are used to represent nodes in the bipartite graph representing the energy system. Furthermore, components are subdivided into Source, Sink and Transformer classes depending on how they are connected to Bus objects. Objects of the class Flow represent the directed edge between two nodes, i.e. the connection between a Bus and a Component object. Moreover, the class EnergySystem serves as a container and holds additional information, like time index information or groups of nodes according to user provided criteria.

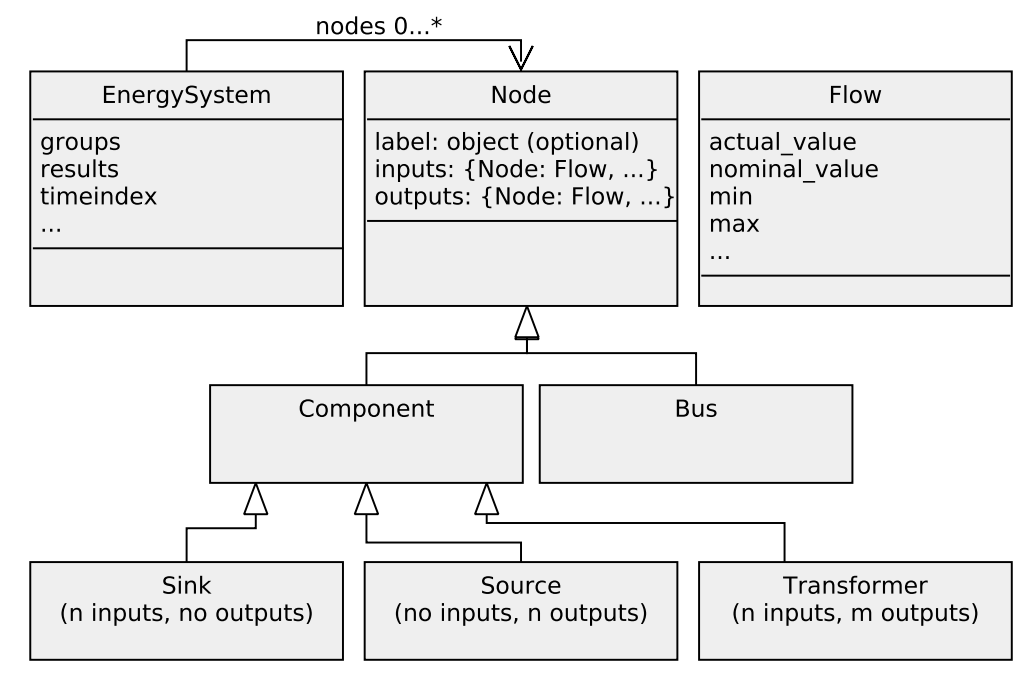

Fig 3. UML diagram of oemof core classes.

All basic energy system components such as energy demands, (renewable) energy sources and transformers between different energy buses can be modelled by means of these basic classes. Additional components that introduce new features can be added via inheritance. If sub-classing is not suitable, new classes can be created and used together with the core classes. As an example, the solph library introduces a storage class with different individual parameters.

The initially outlined main framework feature of a separating the description of the energy system from its simulation is reflected by the introduction of the Flow class which is separate from the Node class hierarchy. Objects of this class hold information about the flow between two nodes such as maximum available transfer capacities of power line flows or whether the amount of a certain flow is fixed and if so, its value. As an example for the provided generic flexibility, objects of this class are used in the solph library to build inter-temporal constraints for different kind of energy system optimization problems such as combined heat and power modelling or unit commitment.

A representation closer to real-world energy systems can be created by the EnergySystem class. The class serves as a container of the above mentioned elements and provides the possibility to add extra information such as grouping structures or optimization parameters. Additionally, it provides interfaces to save results and to save and restore entire energy systems including these results computed from them. This allows for an intuitive handling of energy systems by treating them as an own entity.

Overall, an implementation within the high level programming language Python has the advantage of a rich set of external libraries usable for scientific computing. Oemof itself makes heavy use of external modules for optimization problem and data handling. Additional packages for data pre- and post-processing or visualization can be included easily. The structure empowers the user to decide the extend to which internal 
or external packages should be used in his applications.

\section{Documentation, collaboration and testing}

'A critical part of any piece of software is the documentation' [82, Section IV.A]. This is of particular importance for open source projects with many users and a changing developer base. With the objective of a profound documentation in all stages and formulation of general nomenclature, we follow a documentation approach on four different levels similar to Howells et al. [11]:

(1) Comments inside the code are used to explain non-intuitive lines of code to new developers and interested users at the lowest level.

(2) Docstrings located inside the source code describe the API, i.e. how to use the various classes, methods, and functions.

(3) Higher level descriptions provide the user with additional information about the possible interactions between different libraries or application-specific usage information. These manuals are located inside the repository and are therefore shipped with the source code.

(4) Examples provide an additional source of documentation that is particularly useful to new users.

Keeping such detailed documentation consistent and up to date across releases comes at the expense of a high maintenance effort. Nevertheless, it enables a high degree of transparency which is of special importance if external users want to understand the internal logic of a model in order to reproduce scientific results.

As oemof is an open source community project, a common platform for collaboration is needed. Similar to Greenhall and Christie [82] as well as other open source energy modelling projects, oemof uses GitHub for collaboration, code hosting and bug-tracking which allows for an easy copying and forking of the project. GitHub is based on the version control system git and code can be developed in parallel on different branches. In order to ensure an effective branching strategy and release management, a well established git workflow model [83] is set as standard for all developers. Contributions to the code base are managed in form of pull requests which allow for an openly discussed review process of potential changes. Moreover, code changes are checked for conflicts before being merged back into the development branch by the respective developer in charge of the affected library. Continuous tasks such as bug-fixes, suggestions for improvements and user support are handled via issues and different tags as in most other software projects hosted on GitHub.

In order to test oemof's functionality in case of changes to multiple parts of the code base, unit tests are applied. During the testing process, all integrated application examples are run and the created results are checked against stored historical results. Only if all examples run without errors a pull request is merged back into the development branch. This procedure ensures the functionality even if major changes to the code base are applied from one release version to another.

\section{Applications}

The framework is not designed to constitute a standalone executable. Instead, the oemof libraries are meant to be used in combination with input data, parameters and possibly other Python libraries to build applications that produce concrete results. Applications may depict a specific energy system or provide an abstraction layer to a customisable modelling software (sub-framework).

\section{Application development}

Generally, applications can be developed highly individually by the use of one or more framework libraries depending on the scope and purpose. Fig 4 illustrates the typical process of building an application. This 
time, the libraries are grouped according to their domain when viewed from a potential user's perspective and not according to their layer in the cosmos like in Fig 2.

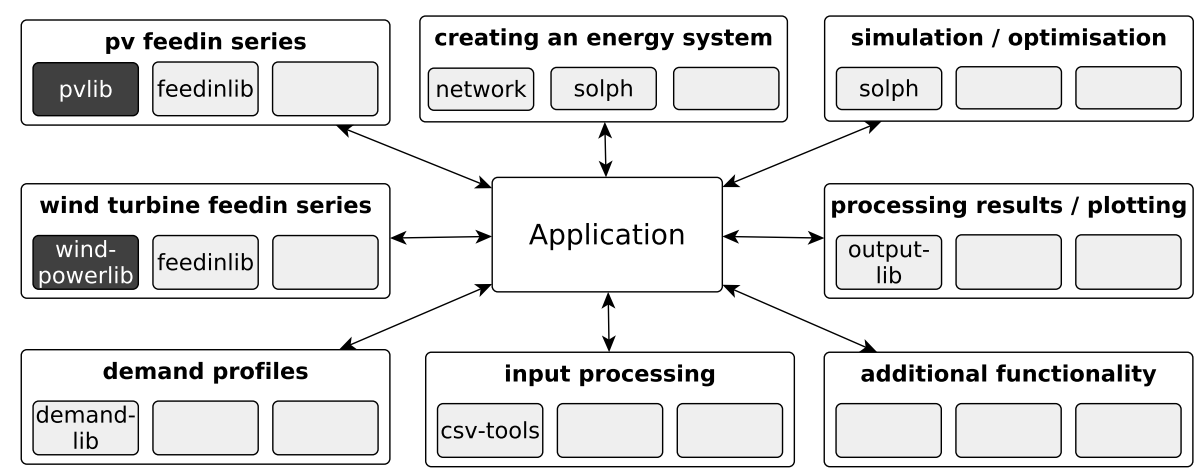

Fig 4. Building an application based on libraries of the oemof cosmos and external libraries (dark grey).

Applications can be built in a flexible way by combining oemof libraries with external Python libraries. When developing applications, specific components can be substituted easily according to the functionality needed, which allows individual application development and provides a high degree of freedom for the developer. This is particularly relevant in working environments such as scientific work groups working spatially distributed and requiring adjustments for specific research questions. Within a modelling process, libraries of the framework are combined to model the desired system with its behaviour in an application. Due to the flexibility mentioned above, modelling processes can take various forms ranging from a few plain steps in a standalone Python file to complex procedures contained in one or spread over more Python packages based on oemof). However, regarding the modelling workflow, all applications have some major steps in common and throughout include all required data pre- and post-processing.

To illustrate the modelling process, Fig 5 shows the schematic workflow of a simple application. First

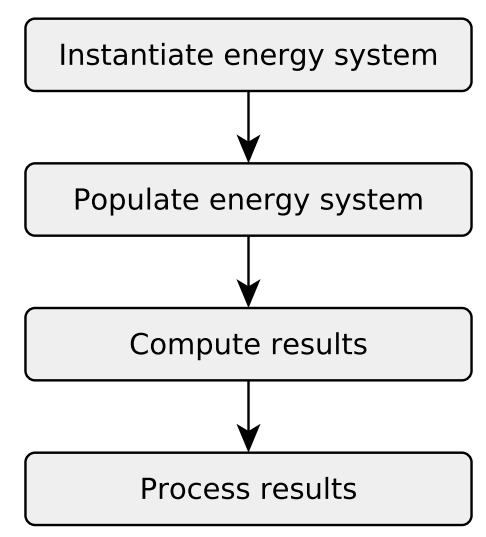

Fig 5. Common steps in the oemof application development workflow.

of all, an empty energy system object is created. This object acts as a container for the nodes and carries information such as the time resolution. Additionally, methods to handle nodes are provided. The next step is the instantiation of nodes and flows of the modelled energy system which are added to the existing energy system instance (population of energy system). Node and flow objects can be created step by step in the 
python programming language whereas large energy models can use their own functions to deal between data and parameter input and the creation of the nodes. One option provided by oemof is the usage of a specially formatted CSV-file in order to define an energy system including its parameters. Subsequently, the results of the energy system can be computed by simulating or optimizing the system. For example an optimization problem based on the network structure is created and solved with the oemof-solph library. This optimization library provides (mixed integer) linear programming methods to optimize energy systems regarding different metrics such as costs or emissions. For the simulation/optimization, objects created from namespace-layer classes may be used as well as core-layer objects. Though, solph-nodes might not be compatible with nodes from another namespace library. Nevertheless, all objects will be compatible with the functionalities of the core-layer. Finally, results can be processed with the output library of oemof. The oemof-outputlib makes it easy to get different views of the results and plots based on a uniform output data format.

Despite all differences, oemof applications share a similar structure, as the steps mentioned above are always present. Therefore, it is easier for developers to comprehend oemof based models than completely different, arbitrary other models.

\section{Existing applications}

The framework already includes a couple of lean exemplary applications demonstrating the basic use cases. These have served as a foundation for more comprehensive applications applied in different research projects [84-88]. In addition, oemof is also used actively in teaching by some institutions. In the following, three applications using oemof for different models are described.

The renewable energy pathways simulation system (renpassG!S) [89] is a bottom-up fundamental Western European electricity market model which is currently developed at the Center for Sustainable Energy Systems (ZNES) Flensburg. It models future scenarios of the power plant dispatch and price formation in Germany and its interconnected neighbouring countries. It is based on operational and marginal costs and assumes an inelastic electricity demand. Currently, a similar spin-off model is adapted to the requirements of the Middle East and North Africa (MENA) region to model possible pathways for the future electricity generation based on a high share of renewable energy sources. Due to oemof's modular structure, it requires minimal effort to change the geographical scope and the focus of the research question.

The Heating System Optimization Tool (HESYSOPT) [90] provides a free, open source tool to simulate district heating systems. It extends functionalities of oemof's namespace layer and its solph library to build a mixed integer linear programming tool for district heating simulation. Classes located in oemof-network are sub-classed in order to increase the granularity at which physical objects can be represented. This is an example of how the object-oriented implementation allows for application specific customization by extending existing functionality via sub-classing.

As a third example, reegis ${ }^{h p}$ [91] models heat and power systems on a local scale with the objective to evaluate district heating and combined heat and power in energy systems based on renewable resources from an environmental and economic perspective. The local system is connected in terms of electricity to a national model based on the idea of the model renpass [12] which is extended to include the heating sector. Local district heating conduits, power plants and storage elements use libraries of the three innermost oemof layers. Feed-in series are automatically created using oemof's feedinlib, open data sets and GIS methods.

These applications illustrate the flexibility of oemof and the extent of the potential user group not only content- and resolution-wise, but also concerning the level of involvement. On one hand it is possible to build a full-scale energy system model adapted to the user's needs by just employing existing functionalities. On the other hand, advanced users which also have development capabilities can add libraries with e.g different optimization algorithms or system components. 


\section{Addressed challenges}

Based on the outlined energy system modelling challenges, the contribution of the presented framework to address those is derived in the following. The contribution of the Open Energy Modelling Framework can be attributed to its three major characteristics which lie in (1) the free and open source software philosophy, (2) the collaborative development and (3) the structural properties (modular framework, object oriented implementation, generic energy system representation, data model). Each of the outlined challenges (i) complexity, (ii) uncertainty, (iii) interdisciplinary modelling, (iv) scientific standards and (v) model utilization is addressed by one or more of the three mentioned characteristics.

Challenges related to complexity are particularly tackled by oemof's structural properties. Challenges associated with scientific standards, model utilization and difficulties of interdisciplinary modelling are primarily addressed by the free and open philosophy and collaborative development. In contrast, uncertainty can not be addressed sufficiently at present.

Although the benefits of these characteristics regarding each specific challenge are difficult to determine; Table 2 attempts to highlight the single peculiarities. The contributions of the specific framework characteristics to the single challenges are discussed below.

Table 2. Contribution of oemof to energy system modelling challenges (the symbols $+/ \mathrm{o} /-$ represent strong/partial/no addressing).

\begin{tabular}{lccl}
\hline Challenge & Contribution & Characteristic & Arguments \\
\hline Complexity & + & $(3)$ & $\begin{array}{l}\text { generic foundation for integrated \& flex- } \\
\text { ible modelling, easy model linking, var- } \\
\text { ious libraries including input \& result } \\
\text { data processing }\end{array}$ \\
\hline Uncertainty & - & $(2)$ & $\begin{array}{l}\text { minor contribution to linguistic \& struc- } \\
\text { tural uncertainty, variability uncertainty } \\
\text { not at all addressed }\end{array}$ \\
\hline Interdisciplinary Modelling & \multirow{2}{*}{$\begin{array}{l}\text { common understanding of system com- } \\
\text { ponents, generic foundation extendible } \\
\text { to other research fields }\end{array}$} \\
\hline Scientific Standards & $(2),(3)$ & $\begin{array}{l}\text { free software, open source and open } \\
\text { data, extensive documentation, repro- } \\
\text { ducibility }\end{array}$ \\
\hline Model Utilization & \multirow{2}{*}{$\begin{array}{l}\text { extensive documentation, similar struc- } \\
\text { ture of oemof application facilitates ap- } \\
\text { plicability, no attribution to result com- } \\
\text { munication }\end{array}$} \\
\hline
\end{tabular}

Characteristics: (1) Free \& open philosophy, (2) Collaborative development, (3) Structural properties

\section{Complexity}

Due to its structural properties, oemof makes it possible to create flexible energy system models which can be easily adapted and connected. For example, modelling strongly integrated energy systems is straightforward in the abovementioned network structure. Energy systems can even be developed separately by different persons and be connected afterwards. If, for instance, a specific sub-system should only appear in certain calculations, it can be connected and disconnected flexibly to the energy system graph with all its components 
depending on the requirements. Additionally, the generic classes can be used to easily integrate other models within oemof. This has for instance been tested with the PyPSA model [67]. Applications built on oemof have shown the integration of electricity, heat and mobility as well as energy market simulation models [86] and power-flow simulations [85].

By sharing essential structural properties, hard- and soft-linking of oemof-based applications can be performed even with different modelling approaches or regional and temporal resolutions. As Trutnevyte et al. [92] argue this can be key for energy system analysis. Furthermore, applications build on oemof's generic structure may be extended by other developers. As explained before and illustrated by different application examples, the object-oriented approach generally provides a flexible interface for extensions. Based on the underlying concept, incorporating new modelling methodologies will be possible in the future (e.g agent-based models based on core components). Moreover, the framework provides a complete toolkit for modelling highly integrated, renewable energy based systems. Thus, not only optimization models can be build, but also input data such as feed-in or demand time series may be generated on the basis of oemof functionalities. Especially the feed-in libraries allow for a high spatial and temporal resolution. Overall, the underlying generic basis in combination with a flexible programming language facilitates the modelling process for complex and changing systems.

\section{Uncertainty}

With its concept, oemof may already contribute to a process of addressing linguistic uncertainty. Identifying common elements in energy system modelling can help in determining coherent terminologies. Here, experiences from collaborative modelling can be a key for the necessary interface definitions of different existing models. Hence, at least ambiguity is tackled as developers have to agree on specific terms during the development process. Multiple perspectives of developers with different backgrounds in the process of collaborative model development decrease the risk to overlook or omit decisive features of energy systems. Hence, with this property, epistemic uncertainty related to model structure uncertainty is partly addressed by oemof as well. At the moment the framework does not provide any functionalities tackling problems of variability uncertainty. Nevertheless, above mentioned techniques to tackle uncertainty such as stochastic programming could be added with reasonable effort since they are already integrated in the underlying Python optimization packages. Furthermore, methods to explore a large space of parameter variations (i.e. scenario or sensitivity analysis) could be easily built on top of an oemof based model.

\section{Interdisciplinary modelling}

The provided framework does not directly address the issue of taking down disciplinary walls between energy system modelling and other research disciplines. Even though oemof is not restricted to a specific mathematical approach, capturing the human dimension is not at the core focus of the framework. Nevertheless, oemof's core package may serve as a base for implementing other methods (e.g. agent-based models). Therefore, the concept of oemof allows to integrate modelling techniques that suit interdisciplinary modelling.

We think, another important contribution can be derived from the collaborative development. This kind of development is not well established in energy system modelling. In the case of oemof, it triggered the process of finding common definitions and understanding of energy research related problems. As a consequence, two important points in terms of interdisciplinary modelling are contributed by oemof: (1) experiences from the collaborative development process can be translated to interdisciplinary model development, (2) the resulting generic basis allows for an easy coupling of energy system model components with new model components of other research areas (e.g. components in water resource modelling). 


\section{Scientific standards}

With a strict free software, open source and open data philosophy, oemof satisfies a basic condition in terms of transparency and allows for repeatability, reproducibility and scrutiny. However, publishing undocumented source code of complex models still represents serious obstacles for others. Therefore, the four level documentation, code-review, and version-control of oemof are important elements for effective transparency. Moreover, oemof provides functionalities to increase transparency on application level. With a standardized input/output data format, simultaneous publishing of model source code and the corresponding documentation (including data) is possible. As explained, for this a human readable, spreadsheet based and thus cross-platform data structure provides a simple user interface and lowers the entry barrier for new users significantly. Supported by a clear version-control workflow, this allows for the release of monolithic model versions including all data and documentation. Thus, scientific model results are not only transparent but also easily reproducible. Additionally, this principle allows a stand-alone run of applications without the need of supplementary software infrastructure (e.g. databases). Hence, applications can also be archived and exchanged easily.

From the beginning of the project, the collaborative framework development with different backgrounds of its developers required a high quality documentation. As a result, transparency is improved for new developers and external users through the mentioned four level documentation. The collaborative framework development of oemof increases the probability of finding bugs. In addition, controversial approaches can be discussed and the results can directly lead to improved code. With these properties, oemof fulfils all six best practice recommendations for repeatable analysis worked out by DeCarolis et al. [13].

\section{Model utilization}

Policy measures and planning processes based on the results of energy system models cannot be affected directly by the modeller. The open source and - depending on the specific application - open data approach enables decision makers and planners to obtain deeper understanding of model results considering details of model inputs. This may enhance communication between modellers, decision makers and other stakeholders. Furthermore, the before-mentioned common terminology enables the different groups to communicate effectively.

Beyond challenges outlined above, oemof supports the energy system modelling community by providing a basis for model development that is highly reusable and adaptable. This could save other resources (e.g. time) in terms of parallel work especially when it comes to long-term projects with a high extent of interfaces between groups and work packages. Therefore, oemof is in line with the argumentation of increased productivity through collaborative burden sharing [65, p.212]. Also, the applicability of oemof models is improved by the underlying structure. Once this structure has been internalized by users and model developers, the model development and usage is straightforward. Through the modular and layer based design - where each layer has a certain degree of interdependency from the remaining part of the framework - new users can create applications based on the desired module without knowledge of the complete framework. Moreover, the overall concept is consistent and the graph-based structure is in line within the code, data and documentation. Thus, even complex cross-sectoral models or applications developed with another scientific scope can be understood quickly. Generally, a well-defined modelling workflow makes things more transparent.

\section{Open challenges and remaining problems}

As described in the previous section and summarized in Table 2 the challenges of scientific standards and complexity are addressed by the presented framework. Subsequently, the open challenges (uncertainty, interdisciplinary modelling, model utilization) and associated remaining problems are discussed. The remaining problems can only partly be addressed by a modelling approach itself. We think some of them are rather located on a meta-level. 
Most types of uncertainty are not tackled by oemof. Thus, future effort should be put in incorporating existing approaches for tackling variability uncertainty. However, existing solutions like sensitivity analysis or stochastic programming counteract complexity, as these measures are computationally expensive. But also by applying existing approaches and under the reasonable assumption of increasing computational resources, modern realities aggravate the problems related to uncertainty. Missing regulatory certainty in combination with disruptive events can hardly be tackled by existing technical methodologies. Hence, policy makers need to be aware that reliable policies and regulatory schemes are crucial for the degree of reliable advice energy modelling can provide as for policy making.

Another open issue exists in terms of structural model uncertainties that are also closely linked to the challenge of complexity. Instead of handling these uncertainties as practical constraints they have to be analysed extensively (e.g. influence of temporal and regional resolution on results). This is important as growing complexity of the modelled systems will necessitate reducing model complexity. In turn, structural uncertainties of these simplified models will increase. Connected to this issue are open questions that directly link to model utilization (e.g. 'Is a model with unquantified structural uncertainties fit for a specific purpose?').

As delineated in section Addressed challenges, oemof lays important foundations for interdisciplinary modelling. Nevertheless, this has not been carried out on the basis of oemof applications so far. Developing common understanding of transdisciplinary problems is a non-trivial task but a basis for interdisciplinary modelling. Here, collaborative development may play an important role in acquiring necessary skills. Besides this, barriers for integrating social sciences in energy system modelling can partly be found in the organizational structure of scientific education and work. Real interdisciplinary work by scientists is still often discriminated against when being evaluated by scientist with deep disciplinary backgrounds.

Regarding model utilization, oemof contributes to model application and re-usability. However, the problem of result communication remains, which can only be addressed on a meta-level. The problem of how results are communicated is a recurring point in literature. Communication of energy system modelling results fails when recipients only see concrete numbers (e.g. total energy system cost) as an outcome. Though, models should firstly be seen as a tool for understanding mechanisms and getting insights [72,73]. This simple idea seems to be ignored on a regular basis but this problem can not be tackled by a model or framework itself. Extended usage of pre-prints and discussions about results and methodologies within the community before the actual publishing process can be one step into the right direction. Proposals to reinvent the modeller-policy decision maker interface made by Strachan et al. [10] also seems promising for overcoming this problem.

\section{Conclusion}

Computer based modelling is a valuable method for understanding complex energy systems and thus inevitable to support decision making. Associated with the modelling process are challenges that are caused by the nature of complex systems and are enforced by the transformation of the energy system. While some challenges exist since the beginning of energy system modelling, others are gaining in magnitude due to modern realities. We categorize the diverse challenges by complexity, uncertainty, interdisciplinary modelling, scientific standards, and model utilization. As argued extensively, oemof contributes to address these challenges based on its characteristics. Being developed in an academic context, challenges related to scientific standards are addressed thoroughly with the free software and open source philosophy. This is also indicated as oemof complies with the best practice recommendations of DeCarolis et al. [13]. Moreover, oemof's structural properties tackle important issues related to complexity. With the generic basis, the modular framework and the object oriented implementation, modelling of integrated renewable energy systems, easy model linking as well as input and result processing is facilitated. Regarding challenges in terms of model utilization, oemof's philosophy constitutes an important precondition for tackling those. Effective transparency at all stages is crucial for result-communication as well as for application and re-usability of models. Moreover, oemof's characteristics, lay important foundations for addressing challenges associated with interdisciplinary modelling. First, the generic basis allows for modelling components originated in other research areas. Second, experiences 
from the collaborative development can be translated to interdisciplinary model development. At present, most types of uncertainty, remain as open challenges. Future effort should therefore be put into tackling variability uncertainty by integrating existing methodologies, such as stochastic programming. Additionally, we recommend to analyse structural uncertainties of energy system models.

Finally, its noteworthy that some approaches with respect to specific challenges may counteract each other. Consequently, challenges cannot be overcome by one single model or framework approach. Instead, a process of applying and analysing different approaches, accompanied by a discussion within the scientific community is necessary to tackle the challenges. This process is particularly relevant as we identify challenges that are recurring problems and can not be tackled solely by technical modelling approaches. Among these are problems of result-communication and interdisciplinary modelling. We argue that these must be primarily addressed through changes in communication, habits and organizational structures. Especially, the fundamental questions if models are fit for purpose and what model results may reveal - or may not reveal - seems to be disregarded way too often. Here again, collaborative modelling can be a valuable method supporting the process.

\section{Acknowledgements}

The group of authors of this paper is not identical with the oemof developer group. Since oemof is a collaborative project all developers can be found on the contributors page of each repository at github. The project was initially created by the following institutions:

- Europa-Universität Flensburg (EUF)

- Flensburg University of Applied Sciences (HFL)

- Otto von Guericke University Magdeburg (OVGU)

- Reiner Lemoine Institut Berlin (RLI) 


\section{References}

1. Kagiannas AG, Askounis DT, Psarras J. Power generation planning: a survey from monopoly to competition. International Journal of Electrical Power \& Energy Systems. 2004;26(6):413-421. doi:http://dx.doi.org/10.1016/j.ijepes.2003.11.003.

2. Wei YM, Wu G, Fan Y, Liu LC. Progress in energy complex system modelling and analysis. International Journal of Global Energy Issues. 2006;25(1/2):109-128. doi:http://dx.doi.org/10.1504/IJGEI.2006.008387.

3. Pfenninger S, Hawkes A, Keirstead J. Energy systems modeling for twenty-first century energy challenges. Renewable and Sustainable Energy Reviews. 2014;33:74-86. doi:http://dx.doi.org/10.1016/j.rser.2014.02.003.

4. Craig PP, Gadgil A, Koomey JG. What can history teach us? A Retrospective Examination of Long-Term Energy Forecasts for the United States. Annual Review of Energy and the Environment. 2002;27:83-118. doi:http://dx.doi.org/10.1146/annurev.energy.27.122001.083425.

5. Hunter K, Sreepathi S, DeCarolis JF. Modeling for insight using Tools for Energy Model Optimization and Analysis (Temoa). Energy Economics. 2013;40:339-349. doi:http://dx.doi.org/10.1016/j.eneco.2013.07.014.

6. Mirakyan A, Guio RD. Modelling and uncertainties in integrated energy planning. Renewable and Sustainable Energy Reviews. 2015;46:62-69. doi:http://dx.doi.org/10.1016/j.rser.2015.02.028.

7. Warr BS, Ayres RU. Evidence of causality between the quantity and quality of energy consumption and economic growth. Energy. 2010;35(4):1688-1693. doi:http://dx.doi.org/10.1016/j.energy.2009.12.017.

8. Chang Y, Li G, Yao Y, Zhang L, Yu C. Quantifying the Water-Energy-Food Nexus: Current Status and Trends. Energies. 2016;9(2):65. doi:http://dx.doi.org/10.3390/en9020065.

9. Schuitema G, Sintov ND. Should we quit our jobs? Challenges, barriers and recommendations for interdisciplinary energy research. Energy Policy. 2017;101:246-250. doi:http://dx.doi.org/10.1016/j.enpol.2016.11.043.

10. Strachan N, Fais B, Daly H. Reinventing the energy modelling-policy interface. Nature Energy. 2016;1(16012). doi:http://dx.doi.org/10.1038/nenergy.2016.12.

11. Howells M, Rogner H, Strachan N, Heaps C, Huntington H, Kypreos S, et al. OSeMOSYS: The Open Source Energy Modeling System: An introduction to its ethos, structure and development. Energy Policy. 2011;39(10):5850-5870. doi:http://dx.doi.org/10.1016/j.enpol.2011.06.033.

12. Wiese F. renpass - Renewable Energy Pathways Simulation System - Open Source as an approach to meet challenges in energy modeling [PhD-Thesis]. Europa Universität Flensburg; 2015.

13. DeCarolis JF, Hunter K, Sreepathi S. The case for repeatable analysis with energy economy optimization models. Energy Economics. 2012;34(6):1845-1853. doi:http://dx.doi.org/10.1016/j.eneco.2012.07.004.

14. Opemod Initiative. open energy modelling initiative: Open Models; 2016. Available online: http: //wiki.openmod-initiative.org/wiki/Open_Models (accessed: 24 June 2016).

15. Dieckhoff C, Eberspächer A. Consulting with energy scenarios - Requirements for scientific policy advice; 2016. Available online: http://www.akademienunion.de/fileadmin/redaktion/user_upload/ Publikationen/Stellungnahmen/Stellungnahme_Energy_scenarios.pdf (accessed 24 June 2016). 
16. Mai T, Logan J, Blair N, Sullivan P, Bazilian M. RE-ASSUME. A Decision Maker's Guide to Evaluating Energy Scenarios, Modeling, and Assumptions; 2013. Available online: http://iea-retd.org/ wp-content/uploads/2013/07/RE-ASSUME_IEA-RETD_2013.pdf (accessed: 24 June 2016).

17. Bazilian M, Rogner H, Howells M, Hermann S, Arent D, Gielen D, et al. Considering the energy, water and food nexus: Towards an integrated modelling approach. Energy Policy. 2011;39(12):7896-7906. doi:http://dx.doi.org/10.1016/j.enpol.2011.09.039.

18. Deane JP, Chiodi A, Gargiulo M, Gallachóir BPO. Soft-linking of a power systems model to an energy systems model. Energy. 2012;42(1):303-312. doi:http://dx.doi.org/10.1016/j.energy.2012.03.052.

19. Deane JP, Gracceva F, Chiodi A, Gargiulo M, Gallachóir BPO. Assessing power system security. A framework and a multi model approach. International Journal of Electrical Power \& Energy Systems. 2015;73:283 - 297. doi:http://dx.doi.org/10.1016/j.ijepes.2015.04.020.

20. Trepper K, Bucksteeg M, Weber C. An integrated approach to model redispatch and assessment of potential benefits from market splitting in Germany. EWL Working paper Series. 2013; (Working paper no. 19).

21. Ravn HF. The Balmorel Model: Theoretical Backround; 2001. Available online: http://balmorel. com/images/downloads/The-Balmorel-Model-Theoretical-Background.pdf (accessed: 17 January 2017).

22. Dodds PE, Keppo I, Strachan N. Characterising the Evolution of Energy System Models Using Model Archaeology. Environmental Modeling and Assessment. 2014;20(2):83-102. doi:http://dx.doi.org/10.1007/s10666-014-9417-3.

23. Hall LMH, Buckley AR. A review of energy systems models in the UK: Prevalent usage and categorisation. Applied Energy. 2016;169:607-628. doi:http://dx.doi.org/10.1016/j.apenergy.2016.02.044.

24. Després J, Hadjsaid N, Criqui P, Noirot I. Modelling the impacts of variable renewable sources on the power sector: Reconsidering the typology of energy modelling tools. Energy. 2015;80:486-495. doi:http://dx.doi.org/10.1016/j.energy.2014.12.005.

25. Connolly D, Lund H, Mathiesen BV, Leahy M. A review of computer tools for analysing the integration of renewable energy into various energy systems. Applied Energy. 2009;87(4):1059-1082. doi:http://dx.doi.org/10.1016/j.apenergy.2009.09.026.

26. Keirstead J, Jennings M, Sivakumar A. A review of urban energy system models: Approaches, challenges and opportunities. Renewable and Sustainable Energy Reviews. 2012;16(6):3847-3866. doi:http://dx.doi.org/10.1016/j.rser.2012.02.047.

27. van Beeck N. Classification of energy models. Tilburg University; 1999. FEW-777.

28. DeCarolis JF. Using modeling to generate alternatives (MGA) to expand our thinking on energy futures. Energy Economics. 2011;33(2):145-152. doi:http://dx.doi.org/10.1016/j.eneco.2010.05.002.

29. Granit J, Fodge M, Hoff H, Jocyce J, Karlberg L, Kuylenstierna J, et al. Unpacking the Water-EnergyFood Nexus: Tools for Assessment and Cooperation Along a Continuum. In: Jägerskog A, Clausen TJ, Lexén K, Holmgren T, editors. Cooperation for a Water Wise World - Partnerships for Sustainable Development. vol. Report Nr. 32; 2013.Available from: http://www.siwi.org/wp-content/uploads/ 2015/09/2013_WWW_Report_web.pdf.

30. Dieckhoff C. Modellierte Zukunft. Energieszenarien in der wissenschaftlichen Politikberatung. No. ISBN 978-3-8376-3097-8 in Science Studies. Bielefeld: transcript Verlag; 2015. 
31. Wiese F, Bökenkamp G, Wingenbach C, Hohmeyer O. An open source energy system simulation model as an instrument for public participation in the development of strategies for a sustainable future. WIREs Energy Environ. 2014;3(5):490-504. doi:https://dx.doi.org/10.1002/wene.109.

32. Ince DC, Hatton L, Graham-Cumming J. The case for open computer programs. Nature. 2012;482:485-488. doi:https://dx.doi.org/10.1038/nature10836.

33. Huntington HG, Weyant JP, Sweeney JL. Modeling for insights, not numbers: the experiences of the energy modeling forum. Omega. 1982;10(5):449-462. doi:http://dx.doi.org/10.1016/0305-0483(82)900020 .

34. Bale CSE, Varga L, Foxon TJ. Energy and complexity: New ways forward. Applied Energy. 2015;138:150159. doi:http://dx.doi.org/10.1016/j.apenergy.2014.10.057.

35. Connolly D, Lund H, Mathiesen BV, Werner S, Möller B, Persson U, et al. Heat Roadmap Europe: Combining district heating with heat savings to decarbonise the EU energy system. Energy Policy. 2014;65:475-489. doi:https://dx.doi.org/10.1016/j.enpol.2013.10.035.

36. Schaber K. Integration of Variable Renewable Energies in the European power system: a model-based analysis of transmission grid extensions and energy sector coupling [PhD-Thesis]. Technical University Munich, Institute for Energy Economy and Application Technology; 2013.

37. Quaschning V. Sektorkupplung durch die Energiewende (Sector coupling by the energy transition); 2016. Study. Berlin University of Applied Sciences (HTW). Available online: http://www . volker-quaschning.de/publis/studien/sektorkopplung/Sektorkopplungsstudie.pdf (accessed on 01 July 2016).

38. Sensfuss F. Assessment of the impact ofrenewable electricity generation on the German electricity sector. An agent-based simulation approach [PhD-Thesis]. University of Karlsruhe; 2007.

39. Wilensky U, Rand W. An Introduction to Agent-Based Modeling: modeling natural, social, and engineered complex systems with NetLogo. MIT Press; 2015.

40. Conzelmann G. Electricity Market Complex Adaptive System (EMACS) - Model Introduction; 2008. Published online by CEEESA, Argonne National Laboratory: http://ceeesa.es.anl.gov/pubs/ 61084.pdf (accessed: 22 December 2016).

41. Richstein JC, Chappin EJ, de Vries LJ. Cross-border electricity market effects due to price caps in an emission trading system: An agent-based approach. Energy Policy. 2014;71:139-158. doi:http://dx.doi.org/10.1016/j.enpol.2014.03.037.

42. Reeg M, Hauser W, Wassermann S, Kast T, Klann U, Nienhaus K, et al. AMIRIS: An Agent-Based Simulation Model for the Analysis of Different Support Schemes and Their Effects on Actors Involved in the Integration of Renewable Energies into Energy Markets. In: 23rd International Workshop on Database and Expert System Applications; 2012. p. 339-344.

43. Krysiak FC, Weigt H. The Demand Side in Economic Models of Energy Markets: The Challenge of Representing Consumer Behavior. Frontiers in Energy Research. 2015;3:24. doi:10.3389/fenrg.2015.00024.

44. Hoffman KC, Wood DO. Energy system modeling and forecasting. Annual review of energy. 1976;1(1):423-453.

45. II JCA, Maier HR, Ravalico JK, Strudley MW. Future research challenges for incorporation of uncertainty in environmental and ecological decision-making. Ecological Modelling. 2008;219(3-4):383399. doi:http://dx.doi.org/10.1016/j.ecolmodel.2008.07.015. 
46. Nijs W, Politis S, Castello PR, Sgobbi A, Thiel C, Zappon F, et al.. Supporting the deployment of selected low-carbon technologies in Europe. Implications of techno-economic assumptions. An energy system perspective with the JRC-EU-TIMES model; 2015. Publication Office of the European Union. EUR 27608 EN. Available online: http://publications.jrc.ec.europa.eu/repository/handle/ JRC99082 (accessed on 07 June 2016).

47. Yeh S, Rubin ES. A review of uncertainties in technology experience curves. Energy Economics. 2012;34(3):762-771. doi:http://dx.doi.org/10.1016/j.eneco.2011.11.006.

48. Nemet GF. Beyond the learning curve: factors influencing cost reductions in photovoltaics. Energy policy. 2006;34(17):3218-3232. doi:http://dx.doi.org/10.1016/j.enpol.2005.06.020.

49. McDonald A, Schrattenholzer L. Learning rates for energy technologies. Energy policy. 2001;29(4):255261. doi:http://dx.doi.org/10.1016/S0301-4215(00)00122-1.

50. Söderholm P, Sundqvist T. Empirical challenges in the use of learning curves for assessing the economic prospects of renewable energy technologies. Renewable energy. 2007;32(15):2559-2578. doi:http://dx.doi.org/10.1016/j.renene.2006.12.007.

51. Ommen T, Markussen WB, Elmegaard B. Comparison of linear, mixed integer and nonlinear programming methods in energy system dispatch modelling. Energy. 2014;74:109-118. doi:http://dx.doi.org/10.1016/j.energy.2014.04.023.

52. Hodges JS, Dewar JA. Is your model talking? A Framework for Model Validation; 1992. Report. Available online: http://www.rand.org/pubs/reports/R4114.html (accessed on February 1 2017).

53. DeCarolis JF, Babaee S, Li B, Kanungo S. Modelling to generate alternatives with an energy system optimization model. Environmental Modelling \& Software. 2016;79:300-310. doi:http://dx.doi.org/10.1016/j.envsoft.2015.11.019.

54. Wardekker JA, van der Sluijs JP, Janssen PHM, Kloprogge P, Petersen AC. Uncertainty communication in environmental assessments: views from the Dutch science-policy interface. Environmental Science \& Policy. 2008;11(7):627-641. doi:http://dx.doi.org/10.1016/j.envsci.2008.05.005.

55. Jefferson M. Closing the gap between energy research and modelling, the social sciences, and modern realities. Energy Research \& Social Science. 2014;4:42-52. doi:http://dx.doi.org/10.1016/j.erss.2014.08.006.

56. Wittmann T. Agent-Based Models of Energy Investment Decisions. Sustainability and Innovation. Heidelberg: Physica-Verlag HD; 2008. Available from: http://link.springer.com/10.1007/ 978-3-7908-2004-1.

57. Robinson SA, Rai V. Determinants of spatio-temporal patterns of energy technology adoption: An agent-based modeling approach. Applied Energy. 2015;151:273-284. doi:http://dx.doi.org/10.1016/j.apenergy.2015.04.071.

58. Rai V, Robinson SA. Agent-based modeling of energy technology adoption: Empirical integration of social, behavioral, economic, and environmental factors. Environmental Modelling \& Software. 2015;70:163-177. doi:http://dx.doi.org/10.1016/j.envsoft.2015.04.014.

59. Fragnière E, Kanala R, Moresino F, Reveiu A, Smeureanu I. Coupling techno-economic energy models with behavioral approaches. Operational Research. 2016; p. 1-15. doi:10.1007/s12351-016-0246-9.

60. Mester KA, Christ M, Degel M, Bunke WD. Integrating social acceptance of electricity grid expansion into energy system modeling: A methodological approach for Germany. In: Conference EnviroInfo 2016. Energy System Modelling - barriers, challenges and good practice in open source approaches. Springer; 2016. p. 115-129. 
61. Christ M, Soethe M, Degel M, Wingenbach C. Wind Energy Scenarios for the Simulation of the German Power System Until 2050: The Effect of Social and Ecological Factors. In: Wohlgemuth V, Fuchs-Kittowski F, Wittmann J, editors. Advances and New Trends in Environmental Informatics. Cham: Springer International Publishing; 2017. p. 167-180. Available from: http://link.springer. com/10.1007/978-3-319-44711-7_14.

62. Sovacool BK. What are we doing here? Analyzing fifteen years of energy scholarship and proposing a social science research agenda. Energy Research \& Social Science. 2014;1:1-29. doi:doi:10.1016/j.erss.2014.02.003.

63. McNutt M. Journals unite for reproducibility. Science. 2014;346(6210):679-679. doi:https://doi.org/10.1126/science.aaa1724.

64. Fehr J, Heiland J, Himpe C, Saak J. Best practices for replicability, reproducibility and reusability of computer-based experiments exemplified by model reduction software. AIMS Mathematics. 2016;1(3):261-281. doi:http://dx.doi.org/10.3934/Math.2016.3.261.

65. Pfenninger S, DeCarolis J, Hirth L, Quoilin S, Staffell I. The importance of open data and software: Is energy research lagging behind? Energy Policy. 2017;101:211 - 215. doi:http://dx.doi.org/10.1016/j.enpol.2016.11.046.

66. Pfenninger S, Keirstead J. Renewables, nuclear, or fossil fuels? Scenarios for Great Britain's power system considering costs, emissions and energy security. Applied Energy. 2015;152:83-93. doi:http://dx.doi.org/10.1016/j.apenergy.2015.04.102.

67. Brown T, Hörsch J, Schlachtberger D. PyPSA: Python for Power System Analysis Version 0.6.1; 2016. Available from: http://pypsa.org.

68. Altman M, Castro E, Crosas M, Durbin P, Garnett A, Whitney J. Open Journal Systems and Dataverse Integration- Helping Journals to Upgrade Data Publication for Reusable Research. Code4Lib Journal. $2015 ;(30)$.

69. Johnson JP. Collaboration, peer review and open source software. Information Economics and Policy. 2006;18(4):477-497. doi:http://dx.doi.org/10.1016/j.infoecopol.2006.07.001.

70. Ndenga MK, Jean M, Ganchev I, Franklin W. Assessing Quality of Open Source Software Based on Community Metrics. International Journal of Software Engineering and its Applications. 2015;9(12):337348. doi:http://dx.doi.org/10.14257/ijseia.2015.9.12.30.

71. Biewald A, Kowarsch M, Lotze-Campen H, Gerten D. Ethical aspects in the economic modeling of water policy options. Global Environmental Change. 2015;30:80-91. doi:https://dx.doi.org/10.1016/j.gloenvcha.2014.11.001.

72. Edenhofer O, Kowarsch M. Cartography of pathways: A new model for environmental policy assessments. Envirionmental Science and Policy. 2015;51:56-64. doi:http://dx.doi.org/10.1016/j.envsci.2015.03.017.

73. Hamming RW. Numerical methods for scientists and engineers. Dover Books on Mathematics. New York: Dover Publications Inc.; 1973.

74. Goldthau A, Sovacool BK. The uniqueness of the energy security, justice, and governance problem. Energy Policy. 2011;41:232-240. doi:https://dx.doi.org/10.1016/j.enpol.2011.10.042.

75. Landry M, Malouin JL, Oral M. Model validation in operations research. European Journal of Operational Research. 1983;14(3):207-220. doi:http://dx.doi.org/10.1016/0377-2217(83)90257-6. 
76. Gilbert AQ, Sovacool BK. Looking the wrong way: Bias, renewable electricity, and energy modelling in the United States. Energy. 2016;94:533-541. doi:http://dx.doi.org/10.1016/j.energy.2015.10.135.

77. Daniels D, Namovicz C. On Inaccuracies in a Published Journal Article; 2016. Available online: https :// www.eia.gov/workingpapers/pdf/White\%20Paper\%20-\%2020160421.pdf (accessed February 22017 ).

78. Wingenbach C, Hilpert S, Günther S. The core concept of the Open Energy Modelling Framework (oemof). In: Environmental Informatics - Current trends and future perspectives based on 30 years of history; 2016.

79. Zeng D, Manfren M. Multi-commodity network flow models for dynamic energy management - Mathematical formulation. Energy Procedia. 2012;14:1380-1385. doi:http://dx.doi.org/10.1016/j.egypro.2011.12.1105.

80. Loulou R, Goldstein G, Noble K. Documentation for the MARKAL Family of Models. Energy Technology Systems Analysis Programme (ETSAP); 2004.

81. Richter J. DIMENSION - A Dispatch and Investment Model for European Electricity Markets; 2011. Available online: http://www.ewi.uni-koeln.de/fileadmin/user_upload/Publikationen/ Working_Paper/EWI_WP_11-03_DIMENSION.pdf (accessed February 2 2017).

82. Greenhall A, Christie R. Minpower: A power systems optimization toolkit. 2012; p. 1-6. doi:10.1109/PESGM.2012.6344667.

83. A successful Git branching model; 2010. Available online: http://nvie.com/posts/ a-successful-git-branching-model (accessed on 31 October 2016).

84. Möller C, Kuhnke K, Reckzugel M, Pfisterer HJ, Rosenberger S. Energy storage potential in the Northern German region Osnabrück-Steinfurt. IEEE; 2016. p. 1-7. Available from: http: //ieeexplore . ieee.org/document/7569497/.

85. Müller UP, Cussmann I, Wingenbach C, Wendiggensen J. In: Wohlgemuth V, Fuchs-Kittowski F, Wittmann J, editors. AC Power Flow Simulations within an Open Data Model of a High Voltage Grid. Cham: Springer International Publishing; 2017. p. 181-193. Available from: http://dx.doi.org/10. 1007/978-3-319-44711-7_15.

86. Degel M, Christ M, Grünert J, Becker L, Wingenbach C, Soethe M, et al. VerNetzen: Sozial-ökologische und technisch-ökonomische Modellierung von Entwicklungspfaden der Energiewende. Projektabschlussbericht. IZT Berlin, Europa-Uniersität Flensburg, Deutsche Umwelthilfe e.V.; 2016. Available from: http://www.uni-flensburg.de/fileadmin/content/abteilungen/industrial/dokumente/ downloads/veroeffentlichungen/forschungsergebnisse/vernetzen-2016-endbericht-online. pdf.

87. Wingenbach C, Hilpert S, Günther S. openMod.SH - Ein regionales Strom-Wärme-Modell für SchleswigHolstein basierend auf open source und open data. In: 14. Symposium Energieinnovation. Technische Universität Graz; 2016.

88. Kaldemeyer C, Boysen C, Tuschy I. Compressed Air Energy Storage in the German Energy System - Status Quo and Perspectives. Energy Procedia. 2016;99:298 - 313. doi:http://dx.doi.org/10.1016/j.egypro.2016.10.120.

89. renpassG!S (Renewable ENergy PAthway Simulation System capable of working with GIS data); 2016. Available online: https://github.com/znes/renpass_gis (accessed on 31 October 2016). 
90. Hilpert S. HESYSOPT - An open source tool to support district heating system flexibilisation. In: Wohlgemuth V, Fuchs-Kittowski F, Wittmann J, editors. Environmental Informatics - Current trends and future perspectives based on 30 years of history. Shaker; 2016. p. 361-366.

91. reegis - An oemof application to model local heat and power systems; 2016. Available online: https: //github.com/rl-institut/reegis_hp (accessed on 31 October 2016).

92. Trutnevyte E, Barton J, Áine O’Grady, Ogunkunle D, Pudjianto D, Robertson E. Linking a storyline with multiple models: A cross-scale study of the UK power system transition. Technological Forecasting and Social Change. 2014;89:26 - 42. doi:http://dx.doi.org/10.1016/j.techfore.2014.08.018.

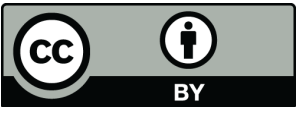

(C) 2017 by the authors; licensee Preprints, Basel, Switzerland. This article is an open access article distributed under the terms and conditions of the Creative Commons Attribution (CC BY) license http://creativecommons.org/licenses/by/4.0/). 